\title{
IN VITRO ANTIBACTERIAL ACTIVITY OF NEEM LEAVES ON EXTENDED-SPECTRUM BETA-LACTAMASE AND AMBLER CLASS C COPRODUCERS FROM SKIN AND SOFT-TISSUE INFECTIONS
}

\author{
PRATIBHA J SHAH ${ }^{1 *}$, MANITA T WILLIAMSON ${ }^{2}$ \\ ${ }^{1}$ Department of Microbiology, K.C. College, Churchgate, Mumbai, Maharashtra, India. ${ }^{2}$ Department of Microbiology, T.N.M.C \& B.Y.L. Nair \\ Charitable Hospital, Mumbai, Maharashtra, India. Email: shahpratij@gmail.com
}

Received: 02 August 2017, Revised and Accepted: 10 October 2017

\section{ABSTRACT}

Objective: Clinical isolates coproducing extended-spectrum beta-lactamase (ESBL) and Ambler Class C (AmpC) beta-lactamase are a therapeutic challenge. The aim of the present study was to evaluate the antibacterial activity of Azadirachta indica methanolic leaf extract against lactose fermenting coproducers of ESBL and AmpC isolated from skin and soft-tissue infections (SSTIs).

Methods: A total of 88 non-duplicate lactose fermenting strains isolated from SSTIs specimens were tested for their antibiotic susceptibility pattern by Kirby-Bauer disk diffusion method. Ceftazidime and cefoxitin-resistant strains were screened for coproduction of ESBL and AmpC beta-lactamase by phenotypic confirmatory disc diffusion test and E-test. Antibacterial activity of methanolic neem leaf (NLM) extract was examined by the disc diffusion method and the minimum inhibitory concentration (MIC) of NLM was determined by the agar dilution technique.

Results: Thirty-seven lactose fermenting strains were confirmed to be coproducers of ESBL and AmpC, out of which 27 were Escherichia coli and 10 were Klebsiella spp. The nimbin content in the neem leaf extract was found to be $0.007 \%$ (w/w) by high-performance liquid chromatography (HPLC) analysis. The NLM extract showed inhibitory activity against all the 37 lactose fermenting isolates from SSTIs, coproducing ESBL and AmpC. The MIC of NLM extract was determined to be in the range of $4-8 \%(40-80 \mathrm{mg} / \mathrm{ml})$ against the selected isolates.

Conclusion: It can be stated that NLM extract might have therapeutic significance against coproducers of ESBL and AmpC beta-lactamase isolated from SSTIs.

Keywords: Extended-spectrum beta-lactamase, Ambler Class C, Azadirachta indica, Skin and soft-tissue infections, E-test, High-performance liquid chromatography.

(c) 2018 The Authors. Published by Innovare Academic Sciences Pvt Ltd. This is an open access article under the CC BY license (http://creativecommons. org/licenses/by/4. 0/) DOI: http://dx.doi.org/10.22159/ajpcr.2018.v11i1.21754

\section{INTRODUCTION}

Beta-lactam antibiotics are among the most commonly used antimicrobials in the world. Extended-spectrum beta-lactamases (ESBLs) are clavulanate susceptible enzymes that hydrolyze penicillins, expanded-spectrum cephalosporins, and monobactams and are commonly inhibited by beta-lactamase inhibitors such as clavulanic acid, sulbactam, and tazobactam [1]. Ambler Class C (AmpC) beta-lactamases are cephalosporinases that are poorly inhibited by clavulanic acid. They can be differentiated from ESBLs by their ability to hydrolyze cephamycins as well as other extended-spectrum cephalosporins [2]. The rapid emergence of Gram-negative bacteria coproducing ESBL and AmpC beta-lactamase pose a challenge in therapeutics, as they mask each other, making their detection difficult. They also cause an increase in the minimum inhibitory concentrations (MIC) of beta-lactam antibiotics and create limitations in the selection of antimicrobial agents [3].

Skin and soft-tissue infections (SSTIs) are the general term used for infections of the entire skin layer, including the subcutaneous and muscle tissue layers and their respective fascia structures. In India, SSTIs may contribute to longer hospital stays, increase the cost of medical care, and play an important role in the development of antimicrobial resistance [4]. Increasing resistance to the beta-lactam group of antibiotics by the Gram-negative pathogens has led to the search of new antimicrobials, from natural products and secondary metabolites of the medicinal plants. After the substantiation of pharmacological effects, medicinal plants can act as natural sources for compounds that could be effective as new antimicrobial agents.
Azadirachta indica (neem) belongs to Meliaceae family and is a very important medicinal plant which is traditionally used to treat different diseases. Almost every part of the tree has been used in traditional system of medicine for the treatment of a variety of human ailments. It has remarkable anti-inflammatory, antibacterial, and antifungal properties [5]. It has been found that neem includes a vast array of biologically active compounds that are chemically diverse and structurally complex. More than 140 compounds have been isolated from different parts of neem. The antibacterial activity of neem might be due to the presence of triterpenoids - bitters, phenolic compounds, carotenoids, steroids, and tetratriterpenoids- azadirachtin [6].

This study aims to investigate the antibacterial activity of methanolic neem leaf (NLM) extract against lactose fermenting coproducers of ESBL and AmpC isolated from SSTIs.

\section{METHODS}

The present study was conducted in a tertiary care hospital and was approved by the local ethics committee of the institution.

\section{Bacterial strains}

A total of 88 non-duplicate lactose fermenting strains isolated from SSTIs of patients from our tertiary care hospital were selected for the study. The samples were processed, and the isolates were identified as per standard laboratory methods [7].

\section{Antimicrobial susceptibility test (AST)}

The antimicrobial susceptibility was determined by Kirby-Bauer disk diffusion method in accordance with the Clinical and Laboratory 
Standards Institute (CLSI) guidelines using commercially available antimicrobial discs (HiMedia, Mumbai, India) [8]. The following antibiotics were used - ampicillin (10 $\mu \mathrm{g})$, amikacin $(10 \mu \mathrm{g})$, ciprofloxacin $(5 \mu \mathrm{g})$, gentamicin $(10 \mu \mathrm{g})$, amoxyclav $(30 \mu \mathrm{g})$, ceftazidime $(30 \mu \mathrm{g})$, cefoxitin $(30 \mu \mathrm{g})$, imipenem $(10 \mu \mathrm{g})$, and piperacillin-tazobactam $(100 / 10)$.

The turbidity of the isolates was adjusted to $0.5 \mathrm{McF}$ arland standards for all the tests. All the isolates which were resistant to ceftazidime and cefotaxime, as per the CLSI susceptible breakpoints were further screened for confirmation of ESBL and AmpC production.

\section{Phenotypic confirmatory disc diffusion test (PCDDT)}

The current CLSI guideline does not describe any method for detection of isolates producing AmpC beta-lactamases. Ceftazidime $(30 \mu \mathrm{g})$ - ceftazidime/clavulanic acid (30/10, HiMedia, Mumbai, India) was used for ESBL detection. If there was $\geq 5 \mathrm{~mm}$ increase in the inhibition zone diameter of ceftazidime/clavulanic acid versus ceftazidime alone, the isolate was considered as an ESBL producer

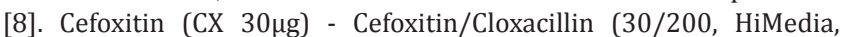
Mumbai, India) discs were used for AmpC detection. An increase of $\geq 4 \mathrm{~mm}$ in the inhibition zone diameter of cefoxitin/cloxacillin acid versus cefoxitin alone indicated AmpC production [9].

\section{E-test}

Detection by phenotypic testing may be misleading, especially when there is a coexistence of ESBL and AmpC. They mask each other, which results in misreporting and failure in the clinical treatment of patients. For this reason, E-strips which differ from conventional strips have been used. Different inhibitors have been applied to improvise the phenotypic tests for beta-lactamase detection.

ESBL and AmpC detection Ezy MIC ${ }^{\mathrm{TM}}$ strip (EM081, HiMedia, Mumbai, India) are drug-impregnated strips in which upper half contains a concentration gradient of four antibiotics; ceftazidime, cefotaxime, cefepime, and cloxacillin plus clavulanic acid and tazobactam and lower half contains of ceftazidime, cefotaxime, cefepime, and cloxacillin in a concentration gradient in a reverse direction. The isolates were reported and confirmed as ESBL and AmpC beta-lactamase producer as per the application sheet supplied by the manufacturer. These strips are to be used along with pure ESBL detection strips (EM079 HiMedia, Mumbai, India) to avoid false positive results [8-11].

A standard reference strain of Escherichia coli ATCC 25922, susceptible to all antimicrobial drugs tested, and positive control strain Klebsiella pneumoniae ATCC 700603 was used as a quality control for AST, confirmatory phenotypic disc diffusion test, and the E-test, as per CLSI guidelines. These phenotypically confirmed coproducers of ESBL and AmpC were selected as test strains, for further studies.

\section{Preparation of NLM extract}

Fresh $A$. indica leaves were purchased from local market. The collected leaves were identified and authenticated by a Botanist at K.C. College, Mumbai. The leaves were separated, washed, and dried in shade. 10 grams of dried and grounded leaves were transferred into a flask containing $150 \mathrm{ml}$ of methanol and Soxhlet extraction was carried out. The extract was filtered and the solvent was evaporated. The dried powder obtained after solvent evaporation was dissolved in $50 \%$ dimethyl sulfoxide (DMSO) to obtain a concentration of $500 \mathrm{mg} / \mathrm{ml}$. The prepared extract was stored at $4^{\circ} \mathrm{C}$ for further use in the study after sterility testing of the extract $[12,13]$.

\section{High-performance liquid chromatography analysis (HPLC)}

The HPLC system consisted of a Shimadzu LC-2010 CHT model (Shimadzu, Tokyo, Japan), with a C18-packed with silanized octadecylsilyl silica gel, $0.5 \mu$ size, $250 \mathrm{~mm} \times 4.6 \mathrm{~mm}$ (Merck) stainless steel column. $20 \mu \mathrm{l}$ of the prepared sample was injected into the HPLC column for the analysis. The elution was carried out at a flow rate of $1.2 \mathrm{ml} / \mathrm{min}$ using the gradient proportion of $100 \%$ acetonitrile and buffer as the mobile phase. For the preparation of buffer, dissolve
$0.136 \mathrm{~g}$ of anhydrous potassium dihydrogen orthophosphate $\left(\mathrm{KH}_{2} \mathrm{PO}_{4}\right)$ in $900 \mathrm{ml}$ of HPLC grade water and add $0.5 \mathrm{ml}$ of orthophosphoric acid. Make up the total volume to $1000 \mathrm{ml}$ with HPLC grade water, filter through $0.45 \mu$ membrane and degas in a sonicator for $3 \mathrm{~min}$ (Natural Remedies, Bangalore, India).

\section{Antibacterial activity of NLM extract}

The evaluation of antibacterial activity of NLM was conducted by the disc diffusion method using Mueller-Hinton agar as described by the CLSI [8]. Sterile paper discs (6 mm, HiMedia, Mumbai, India) were impregnated with $20 \mu \mathrm{l}$ of the $500 \mathrm{mg} / \mathrm{ml}$ NLM extract and placed on the inoculated agar. For the positive control, a disc of imipenem $(10 \mu \mathrm{g})$ and for negative control, a disc impregnated with DMSO was placed on the inoculated Mueller-Hinton agar. The plate was incubated at $37^{\circ} \mathrm{C}$ for $24 \mathrm{~h}$. The experiment was performed in triplicate [13].

\section{Determination of MIC}

The MIC of NLM extract was determined by agar dilution method [14]. For MIC of NLM extract, dilutions were prepared by mixing NLM extract with sterile Mueller-Hinton agar to get final concentrations ranging between $0.25 \%$ and $8 \%(2.5-80 \mathrm{mg} / \mathrm{ml})$. A plate of Mueller-Hinton agar with DMSO served as a control. These plates were seeded with bacterial suspensions and were incubated at $37^{\circ} \mathrm{C}$ for $24 \mathrm{~h}$. The MIC was recorded as the lowest concentration of NLM extract at which visible bacterial growth was completely inhibited. The experiment was performed in triplicate $[13,14]$.

Using the Student's $t$-test, significance of the difference between the mean of zone of inhibition (ZOI) of the NLM extract against $E$. coli and Klebsiella spp. was statistically evaluated.

\section{RESULTS}

Among the 88 lactose fermenting strains isolated from SSTIs, 59 isolates were identified as E. coli and 29 as Klebsiella spp. Out of the 88 lactose fermenting isolates from SSTIs, 78.4\% (69/88) isolates were found to be beta-lactamase producers. Resistance to ceftazidime and cefoxitin was indicative of ESBL and AmpC production, respectively, which was further confirmed by PCDDT and E-test. 42\% (37/88) of the isolates were confirmed to be coproducers of ESBL and AmpC, and these were used as test strains further in the study. Among all the 37 test strains, there were $27 \mathrm{E}$. coli and 10 Klebsiella spp. isolates. Thus, in the current study, $45 \%$ (27/59) of E. coli and 34\% (10/29) of K. pneumoniae isolates were coproducers of ESBL and AmpC producers.

The AST studies of the test strains revealed that carbapenems and aminoglycosides were the most effective antibiotics against the ESBL and AmpC coproducers. All the test strains exhibited a higher resistance rate toward quinolones in comparison with carbapenems and aminoglycosides. Among the two beta-lactamase inhibitors, piperacillin-tazobactam was more effective than amoxyclav against all the test strains. All the coproducers of ESBL and AmpC were also found to be multidrug-resistant, i.e., they were resistant to three or more than three groups of antibiotics (Fig. 1).

The estimation of active ingredient, nimbin was carried out by HPLC analysis and was found to be $0.007 \%(\mathrm{w} / \mathrm{w})$. Primary screening for in vitro antibacterial activity of NLM extract was carried out by disc diffusion method. The extract showed activity against all the 37 lactose fermenting isolates from SSTIs, coproducing ESBL and AmpC. The average ZOI was in the range of $07-13 \mathrm{~mm}$ with a mean of $10.4 \pm 2.33 \mathrm{~mm}$ against the test strains. No ZOI was seen for DMSO used as control. The average ZOI for $E$. coli isolates was found to be $10.72 \pm 2.11 \mathrm{~mm}$ and whereas for Klebsiella spp. isolates it was $10.37 \pm 2.33 \mathrm{~mm}$ (Fig. 2).

The MIC of NLM extract was determined by the agar dilution method. The MIC of NLM extract against all the 37 test strains was found to be in the range of $4-8 \%(40-80 \mathrm{mg} / \mathrm{ml})$, as revealed in Table 1, with a mean of $7.32 \pm 1.35 \%(73.2 \mathrm{mg} / \mathrm{ml})$. The average MIC for E. coli isolates was evaluated to be $7.39 \pm 1.29 \%$ and $7.32 \pm 1.35 \%$ for Klebsiella spp. 
The above table depicts the number and percentage of lactose fermenting isolates inhibited by various minimal concentrations of NLM extract $(n=37)$.

Based on ZOI, the difference in antibacterial activity of NLM extract against E. coli and Klebsiella spp. was statistically insignificant $\left({ }^{*} \mathrm{p}>0.05\right)$. Thus, the antibacterial activity of NLM extract was found to be equivalent for E. coli and Klebsiella spp. isolates, coproducing ESBL and AmpC from SSTIs.

\section{DISCUSSION}

Gram-negative bacilli producing multiple beta-lactamases are very complex antibiotic-resistant pathogens to control and treat. The study of the pattern of bacterial resistance in clinical isolates is important for epidemiological and therapeutic purposes. In the current study, the principal mechanism of beta-lactam resistance was found to be coexpression of ESBL and AmpC beta-lactamases in E. coli and Klebsiella spp. In this study, imipenem was established as the most effective antibiotic for strains which coproduce ESBL and AmpC, followed by aminoglycosides, amikacin, and gentamicin. The resistant rate in the test strains toward third-generation cephalosporins was in accordance with the study carried out by Afroz et al. [15]. The prevalence rate of the coproduction of ESBL and AmpC in lactose fermenters was well-corroborated by a similar study conducted in Mumbai, by Shinde et al. [16].

In the recent past, due to the multidrug-resistance exhibited by coproducers of ESBL and AmpC, carbapenems had been the drug of choice for serious infections [17]. In the current study, all the test strains were multidrug-resistant, but were sensitive to carbapenems,

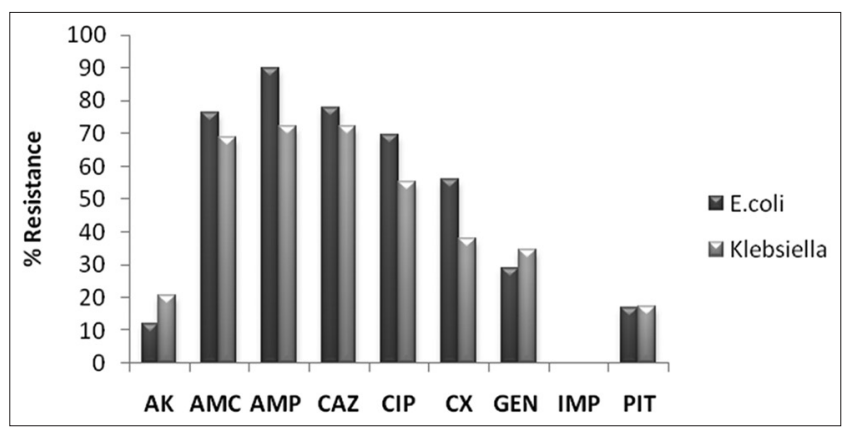

Fig. 1: Rate of antibiotic resistance in E.coli and Klebsiella spp. $(\mathrm{n}=88)$. AK - amikacin, AMC - amoxyclav, AMP - ampicillin, CAZ - ceftazidime, CIP - ciprofloxacin, CX - cefoxitin, GEN - gentamicin, IMP - imipenem, and PIT - piperacillin-tazobactam

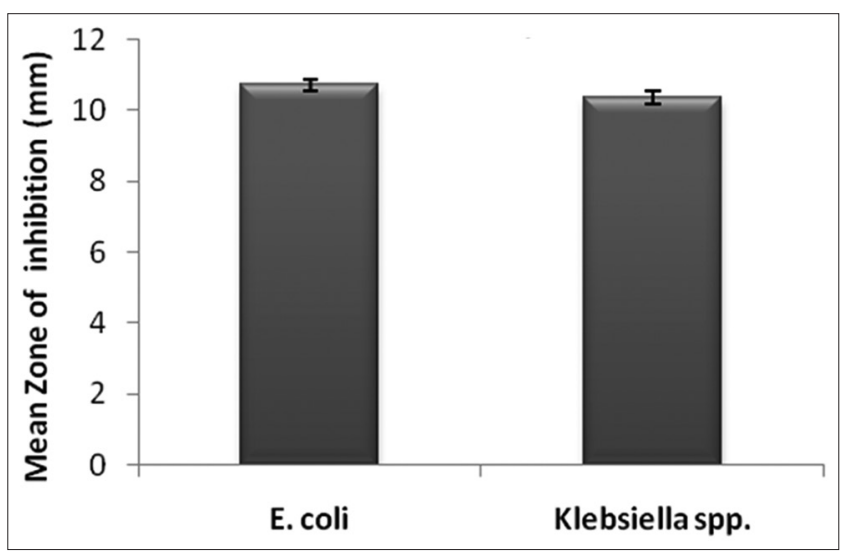

Fig. 2: Mean of zone of inhibition of methanolic neem leaf extract against coproducers of extended-spectrum beta-lactamase and AmpC (data are expressed as mean $\pm S E M, n=3$ ) justifying their usage in empirical therapy. However, carbapenemresistant strains are rapidly emerging; suggesting monitored usage of carbapenems in therapeutics. It is a known fact that beta-lactam inhibitors are ineffective against AmpC producers under in vivo conditions. Conversely, sometimes, false susceptibility patterns are observed, particularly in incidences of coexpression beta-lactamases, leading to erroneous treatment choices [18]. A significant observation of the existing study was the false susceptibility against piperacillintazobactam, in vitro by ESBL and AmpC coproducers. This combination would presumably not be effective under in vivo conditions for isolates producing AmpC. Thus, this evidence suggests that detection of AmpC along with ESBL producers should be performed routinely in the hospitals, to avoid therapeutic failure.

The increasing failure of antibiotics has led to the screening of several plant extracts for their potential antimicrobial activity. The antimicrobial activity of neem leaves has been majorly attributed to bitters like nimbin, which was found in NLM extract in this study [19]. The antibacterial activity of NLM extract was studied using disc diffusion test, and it inhibited all the test strains indicating a potent antibacterial activity against the resistant isolates. Our results are in agreement with the findings of previous studies of Koona and Budida [6] and Chaturvedi et al. [20].

In the current study, the average MIC of NLM extract against the test strains was higher in comparison to the beta-lactam sensitive isolates selected in the study by Dahiya et al. [21] and Emmanuel et al. [22]. In another previous study reported by Shah et al., the MIC values against pure ESBL and pure AmpC producers were also found to be comparatively lower than the current study [13]. On the basis of above comparisons, it can be suggested that a higher concentration of NLM extract is required for inhibition of ESBL and AmpC coproducers. Thus, the higher MIC values in the current study against the selected test strains may be attributed to multiple beta-lactamase production.

There is a paucity of information on antibacterial activity of neem leaves against coproducers of ESBL and AmpC. To the best of our knowledge, the study of antibacterial activity of neem leaf against coproducer of ESBL and AmpC from SSTIs has not been reported earlier.

\section{CONCLUSION}

The evidence summarized above, tentatively suggests neem leaves may have the ability to curb the growing menace of antibiotic-resistant bacteria. The in vitro study proved that NLM extract inhibited lactose fermenting coproducers of ESBL and AmpC isolated from SSTIs. Further, large-scaled and well-designed clinical trials are required to provide more conclusive proof of antimicrobial efficacy of NLM extract. Additional investigation on neem leaves can increase the isolation of the newer molecules which will be helpful for the treatment of SSTIs.

\section{ACKNOWLEDGMENT}

The authors are grateful to the Head of the Microbiology Department, the Bacteriology section in charge of Topiwala National Medical College and B.Y.L. Nair Charitable Hospital, Mumbai, and Dr. Sonal D., botanist K.C. College.

Table 1: MIC of NLM extract against strains coproducing ESBL and AmpC

\begin{tabular}{llllllll}
\hline $\begin{array}{l}\text { Concentration of } \\
\text { NLM (mg/ml) }\end{array}$ & $\mathbf{3 0}$ & $\mathbf{4 0}$ & $\mathbf{5 0}$ & $\mathbf{6 0}$ & $\mathbf{7 0}$ & $\mathbf{8 0}$ & $\mathbf{9 0}$ \\
\hline $\begin{array}{l}\text { Number of strains } \\
\text { inhibited }\end{array}$ & - & 4 & 1 & 2 & 2 & 28 & - \\
$\begin{array}{l}\text { Percentage of strains } \\
\text { inhibited }\end{array}$ & - & 10.8 & 2.7 & 5.4 & 5.4 & 75.7 & - \\
\hline
\end{tabular}

NLM: Methanolic neem leaf, MIC: Minimum inhibitory concentration,

ESBL: Extended-spectrum beta-lactamase 


\section{REFERENCES}

1. Thomson KS. Extended-spectrum-beta-lactamase, AmpC, and carbapenemase issues. J Clin Microbiol 2010;48:1019-25.

2. Sasirekha B, Shivakumar S. Occurrence of plasmid-mediated AmpC $\beta$-lactamases among Escherichia coli and Klebsiella pneumoniae clinical isolates in a tertiary care hospital in Bangalore. Indian $\mathrm{J}$ Microbiol 2012;52:174-9.

3. Sundin DR. Hidden beta-lactamases in the Enterobacteriaceaedropping the extra disks for detection, Part II. Clin Microbiol Newslett 2009;31:47-52.

4. Mohanty S, Kapil A, Das BK, Dhawan B. Antimicrobial resistance profile of nosocomial uropathogens in a tertiary care hospital. Indian $\mathrm{J}$ Med Sci 2003;57:148-54.

5. Yuvaneswaran K, Wong NK. Cytotoxicity and antimicrobial properties of neem (Azadirachta indica) leaf extracts cytotoxicity and antimicrobial properties of neem (Azadirachta indica) leaf extracts. Int J Pharm Pharm Sci 2015;7:179-82.

6. Koona S, Budida S. Antibacterial potential of the extracts of the leaves of Azadirachta indica Linn. Notulae Sci Biol 2011;3:65-9.

7. Colle JG, Miles RS, Watt B. Test for the identification of bacteria. In: Collee JG, Faser AG, Marmion BP, Simmons A, editors. Mackie and McCartney Practical Medical Microbiology. $14^{\text {th }}$ ed. London: Churchill Livingstone; 1996. p. 131-45.

8. Clinical and Laboratory Standards Institute. Performance Standards for Antimicrobial Disc Susceptibility Tests: Approved Standard, CLSI Document M02-A11. $11^{\text {th }}$ ed. Wayne PA: CLSI; 2012.

9. Shah PJ, Williamson MT. Antibacterial and synergistic activity of Calendula officinalis methanolic petal extract on Klebsiella pneumoniae co-producing ESBL and AmpC Beta-lactamase. Int J Curr Microbiol Appl Sci 2015;4:107-17.

10. Rathod SJ, Williamson MT. Antibacterial activity of green tea extract in combination with cefotaxime on diarhea causing ESBL producing E.coli. Int J Pharm Pharm Sci 2015;7:258-62.

11. Shah PJ, Williamson MT. Antibacterial activity of honey against ESBL producing Klebsiella pneumoniae from burn wound infections. Int J Curr Pharm Res 2015;7:32-6.

12. Bimakr M, Rahman RA, Taip FS, Ganjloo A, Salleh LM, Selamat J, et al.
Comparison of different extraction methods for the extraction of major bioactive flavonoid compounds from spearmint (Mentha spicata L.) leaves. Food Bioprod Process 2011;89:67-72.

13. Shah PJ, Williamson MT, Rathod SJ. Antibacterial effect of methanolic neem leaf extract on ESBL, AmpC and MBL producers from skin and soft tissue infections. Int J Pharm Res Biosci 2016;5:117-28.

14. Ward PB, Carson M, Dodd JS, Pavillard ER. Prediction of sulfamethoxazole-trimethoprim synergistic action against members of the family Enterobacteriaceae with a two-plate agar dilution breakpoint MIC system. J Clin Microbiol 1984;19:899-901.

15. Afroz Z, Metri BC, Jyothi P. Bacteriological profile and antimicrobial susceptibility pattern of skin and soft tissue infections among gram negative Bacilli in a tertiary care hospital of south India. J Pharm Sci Res 2015;7:397-400.

16. Shinde S, Nataraj G, Mehta P. Multiple Beta-lactamase resistance mechanism in Escherichia coli and Klebsiella pneumoniae. Bombay Hosp J 2013;55:32-9.

17. Mugnier P, Poirel L, Pitout M, Nordmann P. Carbapenem-resistant and OXA-23-producing Acinetobacter baumannii isolates in the United Arab Emirates. Clin Microbiol Infect 2008;14:879-82.

18. Pai H, Kang C, Byeon J, Lee K, Park W, Kim H, et al. Epidemiology and clinical features of bloodstream infections caused by AmpC Type $\beta$-lactamase producing Klebsiella pneumoniae. Antimicrob Agents Chemother 2004;48:3720-8.

19. Gomase PV, Rangari VD, Verma PR. Phytochemical evaluation and hepatoprotective activity of fresh juice of young stem (tender) bark of Azadirachta indica. Int J Pharm Pharm Sci 2011;3 Suppl 2:55-9.

20. Chaturvedi P, Bag A, Rawat V, Jyala N, Satyavali V, Jha PK. Antibacterial effects of Azadirachta indica leaf and bark extracts in clinical isolates of diabetic patients. Natl J Integr Res Med 2011;2:5-11.

21. Dahiya P, Purkayastha S. Phytochemical screening and antimicrobial activity of some medicinal plants against multi-drug resistant bacteria from clinical isolates. Indian J Pharm Sci 2012;74:443-50.

22. Emmanuel N, Ifeanyichukwu I, Chika E, Emmanuel E, Nwankwo C. Inhibitory effects of neem (Azadirachta indica Linn.) and bitter Kola (Garcinia kola Heckel) leaves on selected pathogenic bacteria. Afr J Pharm Pharmacol 2013;7:2763-7. 